\title{
Auto-Avaliação das Instituições de Ensino Superior
}

\author{
LÉA DEPRESBITERIS \\ Mestre em Tecnologia Educacional pelo Instituto de Pesquisas Espaciais de São \\ José dos Campos e Doutora em Ciências da Educação, pela USP. Mediadora no \\ Programa de Enriquecimento Instrumental, níveis I e II - pelo International Center \\ for Enhancement of Learning Potential - ICELP, em Israel \\ leateris@uol.com.br
}

\begin{abstract}
Resumo
Este artigo pretende convidar você a refletir sobre a avaliação das instituições de ensino superior, sobretudo a etapa de auto-avaliação. Do latim actus, que significa movimento, impulso, ação, a auto-avaliação pode ser vista como um movimento para dentro, uma ação de compreensão de como somos para nos auto-regularmos, ou seja, melhorar nosso interior. Aplicada às instituições de ensino superior, a auto-avaliação exige, além dessa viagem interna, a agregação do "olhar" externo, imprescindível para uma análise multivariada, que considere várias fontes de informação, diversos critérios e indicadores com base em sua missão, políticas, infra-estrutura, planejamento e avaliação, responsabilidade social e outras dimensões importantes. Neste artigo, sugerem-se algumas premissas para a auto-avaliação institucional, destacando-se uma dimensão ética fundamental que, de acordo como Morin (2003), é a auto-ética. Com base nesse estudioso, o artigo discorre, ainda, sobre a idéia de que: "Para se reconciliar consigo, é preciso primeiro brigar consigo. É preciso distanciar-se de si mesmo para se encontrar".
\end{abstract}

Palavras-chave: avaliação, instituições de ensino superior, auto-regulação, auto-ética.

\section{Resumen}

Este artículo desea invitarle a reflexionar sobre la evaluación de las instituciones de la enseñanza superior, sobre todo en la etapa de la auto-evaluación. Del latín actus, que significa movimiento, impulso, acción, la auto-evaluación puede verse como un movimiento hacia dentro, una acción para comprender como somos, para auto-regularnos, o sea, para mejorar nuestro interior. Aplicada a instituciones de la enseñanza superior, la auto-evaluación exige, además de este viaje interior, la añadidura de la "mirada" externa, imprescindible para hacer un análisis múltiple, que considere varias fuentes de información, diversos criterios e indicadores basados en su misión, políticas, infraestructura, planeamiento y evaluación, responsabilidad social y otros aspectos importantes. En este artículo, se sugieren algunas premisas para la auto-evaluación institucional, poniendo de relieve una dimensión ética fundamental que, de acuerdo con Morin (2003), es la auto-ética. Basado en este estudioso, el artículo discurre, aún, sobre la idea de que: "Para reconciliarse consigo propio, es necesario primero, pelearse con uno mismo. Es preciso distanciarse de sí mismo para encontrarse".

Palabras-clave: evaluación, instituciones de la enseñanza superior, auto-regulación, autoética. 


\begin{abstract}
With this article I would like to invite you to reflect on the evaluation of institutions of higher education, mainly on the phase of self-evaluation. From the Latin actus - meaning movement, impulse, action -, self-evaluation may be seen as a movement inwards, an action understanding what we are like so we can self-regulate ourselves, that is, improve our innermost self. When applied to institutions of higher education, self-evaluation demands, besides this inner voyage, the addition of an external "look", absolutely essential for a multivaried analysis which takes into account various sources of information, several criteria and mission-based indicators, policies, infra-structure, planning and evaluation, social responsibility and other important dimensions. This article suggests some premises for institutional self-evaluation, highlighting a fundamental ethical dimension which, according to Morin (2003), is self-ethical. Still based on this scholar, the article discusses the idea that "To reconcile oneself with oneself, one first has to fight oneself. One has to stand at a distance of oneself to find oneself".
\end{abstract}

Key words: evaluation, institutions of higher education, self-regulation, self-ethics. 


\section{PALAVRAS INICIAIS}

Em uma definição simples, a auto-avaliação pode ser sucintamente definida como o ato de uma pessoa avaliar a si própria. No cotidiano, quando nos olhamos no espelho, provavelmente estamos nos autoavaliando: nossa fisionomia, nosso corpo, um gesto determinado. Algumas vezes as impressões são favoráveis, outras desfavoráveis e a maior preocupação é melhorar o que for possível. Quando falo de auto-avaliação, sempre me recordo de um belo poema de Cecília Meireles, intitulado Retrato:

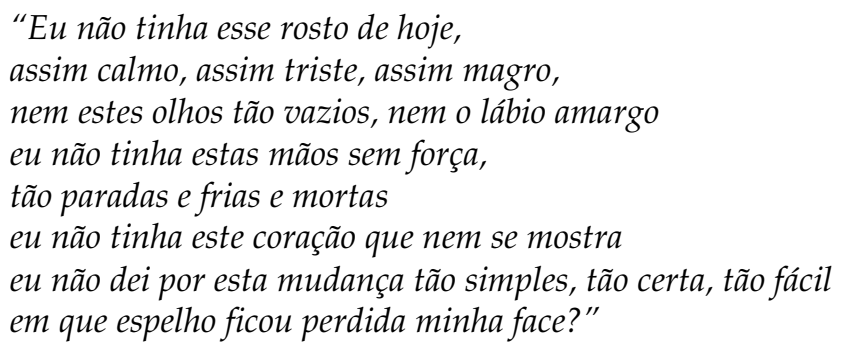

Ao ler esses versos, penso na coragem como elemento fundamental para se realizar uma auto-avaliação. Não é nada fácil desnudar-se. Mais difícil, ainda, é agir para mudar, o que exige disposição, paciência, humildade. Analogamente, uma auto-avaliação institucional utiliza-se daqueles elementos de uma auto-avaliação pessoal. Creio, então, que os mesmos sentimentos e as mesmas condições deverão ser consideradas, uma vez que são pessoas que fazem a auto-avaliação. Afinal, a instituição envolvida com a melhoria de sua qualidade educacional certamente encontrará processos e resultados satisfatórios, mas também deparar-se-á com inadequações.

A auto-avaliação supõe crítica e afastamento para reflexão, estimulando um diálogo interno construtivo. Contudo, auto-avaliar-se não basta; é preciso agir para uma auto-regulação, automodificação.

A auto-regulação não é o mesmo que autocontrole. Quando falamos de autocontrole, referimo-nos a um componente natural da ação no processo. $\mathrm{O}$ autocontrole corresponde a uma avaliação contínua, algumas vezes implícita e quase inconsciente da ação. O controle, aqui, não tem sentido negativo, busca favorecer o olhar da pessoa sobre suas realizações. É como se a pessoa se olhasse no agir constante, a partir de um modelo ideal ou de um sistema de normas.

A atividade de autocontrole está presente na auto-avaliação, mas o que caracteriza com precisão esta última é a chamada auto-regulação. A 
auto-regulação implica em transformações constantes. No que diz respeito à regulação de uma instituição, não são suficientes a auto-regulação por si só, e a simples regulação pelo mercado. Torna-se necessária a constituição de um corpo de atores que integre os diferentes interessados no sistema de avaliação, em nível acadêmico (regional e local) e que se assuma como responsável, tanto pela avaliação institucional quanto pela sua melhoria.

A decisão de se auto-regular, de modificar-se envolve uma outra difícil etapa: complementar as impressões internas com uma avaliação externa. É preciso considerar que freqüentemente nos avaliamos, mas não ouvimos as vozes externas, muitas vezes dolorosas, mas necessárias. Como curiosidade ilustro essa afirmativa com um caso narrado por uma amiga. Ela me contou que um dia estava se maquiando para uma festa, sendo observada por sua sobrinha de cinco anos de idade. A menina que olhava com atenção a colocação da base no rosto, os traços cuidadosos feitos pela tia ao pintar os olhos e o cuidado no ato de passar o batom, perguntou-lhe:

- Tia, por que a senhora está passando essas coisas?

- Para ficar bonita para a festa.

- E por que não fica? considerou a pequena, com uma franqueza de arrepiar.

O olhar externo é importante para conhecermos a nós mesmos. Essa perspectiva "de fora" nos permite integrar o olhar do outro em nosso esforço de autocompreeensão (Morin, 2005).

$\mathrm{Na}$ auto-avaliação institucional, os resultados deverão ser submetidos ao olhar externo de especialistas de áreas/cursos, de planejamento e de gestão da educação superior. As ações de avaliação interna e externa devem ser realizadas de forma combinada e complementar, devendo prevalecer, em ambas, plena liberdade de expressão e busca de rigor e justiça. A instituição deve esforçar-se para motivar a comunidade e para envolver vários de seus setores a participarem dos processos avaliativos. A avaliação externa pode ajudar a suplantar certas ilusões de percepção interna, decorrentes de rotinas, o que impede uma visão crítica fundamentada. Deve-se evitar, igualmente, o uso da auto-avaliação como uma justificativa, uma defesa daquilo que se está desenvolvendo e não como uma projeção futura de melhoria.

O tema de auto-avaliação, proposto no Programa de Avaliação Institucional das Universidades Brasileiras - Paiub (Brasil, 1993) e que foi retomado pelo Sistema Nacional de Avaliação da Educação Superior Sinaes - nos faz refletir ainda mais a respeito dessa difícil tarefa. O Sinaes (Brasil, 2004) foi constituído a partir do trabalho da Comissão Especial de Avaliação (CEA), designada por Portaria da Sesu em 28 de abril de 2003, "com a finalidade de analisar, oferecer subsídios, fazer recomendações, propor 
critérios e estratégias para a reformulação dos processos e políticas de avaliação da Educação Superior e elaborar a revisão crítica dos seus instrumentos, metodologias e critérios utilizados".

O Sinaes é um sistema de avaliação global e integrado das atividades acadêmicas, composto por três processos diferenciados:

- avaliação das instituições de ensino superior, que se desenvolve em duas etapas: a auto-avaliação (coordenada pela Comissão Própria de Avaliação de cada instituição) e a avaliação externa (realizada por comissões designadas pelo Instituto Nacional de Estudos e Pesquisas, segundo diretrizes estabelecidas pelas Comissões Nacionais de Avaliação do Ensino Superior - Conaes);

- avaliação dos cursos de graduação por meio de instrumentos e procedimentos e que incluem visitas de comissões externas à instituição. A periodicidade desta avaliação depende diretamente do processo de reconhecimento e da renovação desse reconhecimento, a que estão sujeitos os cursos;

- avaliação do desempenho dos estudantes (Enade), que se aplica aos alunos do final do primeiro e do último ano, adotando-se procedimentos amostrais.

Minha intenção neste artigo é discorrer sobre algumas premissas que deveriam orientar a reflexão da primeira etapa (avaliação institucional), sobretudo no que se relaciona à auto-avaliação. Nesse sentido, a avaliação institucional é apresentada como um processo global, que permeia as diferentes dimensões acadêmicas: ensino, pesquisa, extensão e gestão universitária, buscando envolver toda a comunidade da instituição, nas dimensões interna e externa. A proposta é que, como partes de um mesmo sistema de avaliação, essas fases sejam desenvolvidas em situações e momentos distintos, fazendo uso de instrumentos próprios e articulados entre si. Nesse momento, surge uma questão candente:

- Será que as instituições de educação superior conseguirão engajar-se de maneira comprometida, responsável, em benefício de seu autoconhecimento para melhorar sua prática?

A história nos mostra algumas tentativas de auto-avaliação das instituições de ensino superior. Creio, contudo, que poucas são as avaliações que realmente desenvolveram uma atitude avaliativa, constante e sistemática. Esperemos que isso ocorra com essa tentativa de avaliação proposta pelo Sinaes. 


\section{O PAPEL DA AUTO-AVALIAÇÃO}

Morin (2005, p.94), ao mencionar a citação de Jung, "a humanidade sofre de uma imensa carência introspectiva", relembra a dificuldade da introspeção. Uma das dificuldades que Morin (op. cit) aponta é a nossa tendência para autojustificação que sempre transfere para o outro o erro ou a falha. Trata-se de um mecanismo, pelo qual cada um se inocenta, se legitima e se promove.

Ainda segundo esse autor, a introspeção necessita do pleno uso das capacidades de auto-análise e autocrítica, o que constitui a auto-ética. A auto-ética exige, ao mesmo tempo, "trabalhar para pensar bem" e "pelo pensar-se bem". Exige, igualmente, a integração do observador na sua observação, o retorno sobre si mesmo para se objetivar, compreender e corrigir-se, o que caracteriza, simultaneamente, um princípio de pensamento e uma necessidade ética.

O exercício permanente da auto-observação suscita uma nova consciência que permite que nos descentralizemos em relação a nós mesmos; logo, de reconhecer nosso egocentrismo e (de) medir o grau de nossas carências, lacunas, fraquezas.

Creio que as avaliações institucionais também deveriam estimular a auto-ética, na busca de uma maior consciência da realidade.

Allal (apud Grégoire, 2000) propõe um esboço para articular um processo de auto-avaliação: uma fase de antecipação, constituída de atividades de previsão para orientar a ação; uma fase de controle, que consiste num processo contínuo de comparação entre um estado dado e um resultado a ser alcançado; e uma fase de ajuste, que é a regulação propriamente dita. Esse processo avaliativo pode abarcar instrumentos formais e informais de coleta de informações que, integrados, possibilitarão uma visão abrangente da instituição. Patton (apud Worthen, 2004) ressalta que o desafio de avaliar é obter a melhor informação possível para as pessoas que delas precisam e, então, fazer com que estas pessoas realmente usem os dados, de forma apropriada, para os propósitos desejados.

Com base nas dez dimensões propostas pelo Sinaes, algumas questões afiguram-se como necessárias. A instituição está:

- cumprindo sua missão e aprendendo com a realidade para renová-la e vislumbrar novos e mais promissores caminhos?

- promovendo o conhecimento de sua missão pela comunidade acadêmica e comunidade externa?

- imprimindo qualidade às sua ações de ensino, pesquisa e extensão? 
- obtendo indícios da concretização de sua responsabilidade social? Recuperando, reconhecendo e respeitando a história da cultura local?

- fomentando a comunicação constante com a comunidade interna e externa?

- adotando políticas de aperfeiçoamento e comprometimento com seus profissionais e alunos?

- sendo gerida com premissas, como participação, autonomia e respeito?

- oferecendo as condições essenciais para um trabalho de qualidade?

- planejando e avaliando suas ações com vistas à melhoria da qualidade?

- permitindo o acesso e incentivando a diversidade de alunos que a procuram ou dela já fazem parte? Buscando compreender a inserção dos ex-alunos na sociedade?

- realizando ações para uma real sustentabilidade financeira?

Como pode se observar, muitas são as questões. Responder a todas elas seria impossível. Contudo, não tentar buscar indicadores mais específicos em algumas delas seria fugir ao trabalho avaliativo. Realizar a auto-avaliação nos tradicionais moldes de controle de um "chek-list" previamente definido também não me parece a solução mais adequada. $\mathrm{O}$ excesso de controle, por meio de listas com itens pré-definidos, pode servir mais ao controle do que a uma real avaliação.

Assim, perguntas como as que foram anteriormente apresentadas são importantes, mas não devem ser consideradas como as únicas e as mais relevantes. Elas mostram o aspecto formal da avaliação, mas muitas vezes não desvelam o que ocorre em termos de mudança de atitudes. Além disso, a instituição deveria levantar questões que desvelem a própria concepção do que ela representa, na atualidade, como uma instituição de ensino superior. Na verdade, o que deveria ser levado em conta não é exclusivamente o desempenho de uma instituição de ensino superior, mas sua função social.

Cumpre ressaltar, porém, que a avaliação é apenas uma parte do processo. Ela serve para identificar potencialidades e limitações, iluminando os aspectos necessários a serem aperfeiçoados. Porém, ela de nada valerá se a realidade não for transformada para melhor. As avaliações, como diz Vianna (2003, p.10), apenas apontam problemas, não os solucionam. 


\section{ALGUMAS PREMISSAS DE AVALIAÇÃO}

fundamentais:

Em termos de avaliação algumas premissas parecem ser

\section{- A avaliação deve preservar a autonomia institucional}

O princípio da autonomia universitária baseia-se no entendimento correto de que cada instituição é o melhor juiz das suas condições concretas, e é quem melhor pode tomar as decisões com relação ao seu funcionamento. Espero que a avaliação das instituições de ensino superior não fira esse princípio, mas, ao contrário, que a autonomia seja ampliada, deixando que as instituições, sejam elas públicas ou privadas, definam os seus perfis, os cursos que querem oferecer e a sua forma de organização. Cumpre ressaltar, porém, que a autonomia deve vir permeada de responsabilidade, expressa em formas rigorosas e abrangentes de avaliar os processos e produtos das instituições na busca de sua missão.

\section{- A avaliação precisaria ser concretizada em sua dimensão formativa}

Trata-se de vislumbrar a auto-avaliação em sua essência educativa, formativa e formadora que faça refletir sobre como a instituição está construindo conhecimento em relação à sua realidade. Isso exige compreender o significado do conjunto de suas atividades, melhorar sua qualidade educativa e, desse modo, alcançar uma maior relevância social. Nesse contexto, torna-se inadequada a concepção de uma avaliação pontual que não permita estabelecer relações entre presente, passado e futuro.

Feuerstein (apud Souza, 2004) enfatiza que essa relação é um dos fatores mais importantes de uma transmissão cultural. Para fundamentar sua opinião, traçou uma analogia com o instrumento do arco e flecha. A distância a ser percorrida pela flexa é uma função direta do grau da torção para trás que se dá à corda do arco. Quanto mais a corda for puxada para trás, mais longe a flecha vai ser projetada. Da mesma maneira, quanto mais um povo sabe a respeito de sua cultura, melhor entende as possibilidades para uma mudança da realidade.

Aplicando-se essa imagem a uma instituição de ensino superior, pode-se inferir a necessidade de se resgatar sua história, sua origem, seus valores, de modo que seus atores compreendam melhor seu contexto atual e suas possibilidades no futuro. Todas essas informações servirão para imprimir à avaliação um aspecto criterial e não normativo. A avaliação normativa impõe a comparação entre instituições, que na realidade não 
possuem as mesmas condições e seguiram diferentes trajetórias. A avaliação criterial tem um caráter essencialmente formativo: os resultados serão analisados com base em parâmetros definidos na missão institucional e com eles deverão ser comparados.

\section{- A avaliação deveria favorecer a participação conjunta e a assunção de responsabilidades}

A avaliação formativa estimula a participação conjunta desde o planejamento até a própria avaliação. Incentiva, também, a assunção individual e coletiva de responsabilidades. Não estamos nos referindo apenas às responsabilidades que estão diretamente ligadas a funções, cargos, atividades, mas à responsabilidade mencionada por Saviani (apud Goergen, 2002, p.70): atitude assumida em decorrência da consciência de certos valores e princípios que, por sua vez, são compromissos históricocríticos. Nesse sentido, ensinar e pesquisar devem ser encarados como gestos responsáveis. Goergen (2002) indica algumas questões propostas por Jacques Derrida quando se fala de responsabilidade. Para Derrida, estaremos dentro do requisito mínimo de responsabilidade, quando buscarmos respostas a algumas dessas questões: Quem somos na universidade em que estamos? $\mathrm{O}$ que representamos? Quem representamos? Somos responsáveis pela atuação institucional, em que aspectos?

Responsabilidades reconhecidas individualmente são importantes, mas não suficientes. É preciso firmar responsabilidades coletivas. À luz dessa afirmativa, Ruiz (1999) aponta a necessidade do paradigma do colegiado, pelo qual se propõe uma ruptura do individualismo e conseqüente estímulo ao trabalho integrado. Nosso grande mestre Paulo Freire (1987) reconhecia a existência de uma dimensão individual e, simultaneamente, coletiva. Ele dizia que ninguém se conscientiza separado dos outros, ninguém evolui sozinho. Freire reforça a idéia do coletivo quando diz que os homens se educam entre si, mediados pelo mundo.

Saul (1988) detalha quais seriam os três momentos de uma crítica institucional e criação coletiva: expressão e descrição da realidade, crítica ao material expresso e criação coletiva, com vistas à emancipação.

A expressão e descrição da realidade incluem a verbalização e a problematização de uma dada realidade, ou seja, como um grupo particular consegue apreendê-la. No âmbito de uma instituição educacional, esta fase se inicia com questões de ordem pedagógica e estende-se a outras questões de natureza político-sociais. A crítica do material expresso implica um recuo crítico do grupo de atores 
institucionais. A própria prática do grupo é analisada para permitir tomada de consciência das possíveis distâncias entre propostas educativas e ações reais. Nessa fase, procura-se explicitar as contradições existentes nas ações dos grupos. A criação coletiva prevê o delineamento de mudanças necessárias na instituição. Explicita-se um projeto político-pedagógico, indicando responsabilidades e compromissos.

Para Saul (op.cit), o produto final de um processo de crítica institucional e criação coletiva não é a elaboração de um relatório, embora muitas vezes ele seja necessário e útil. O mais relevante é a possibilidade de as pessoas envolvidas, ao se tornarem mais conscientizadas de suas aspirações, possibilidades e limites, encontrarem soluções criadoras para os problemas encontrados.

Responsabilidades individuais e colegiadas vão necessitar de um cenário que leve em conta um novo dimensionamento do tempo, dos espaços para reflexão, de dinâmicas de trabalho diferentes, de posicionamentos.

\section{- A avaliação deveria favorecer ao empowerment e à negociação}

Fetterman (apud Worthen, 2004) define empowerment como o desenvolvimento de um processo avaliativo, no qual avaliados e avaliadores compartilham o poder de avaliar. Para este estudioso, a avaliação deve emancipar, liberar, esclarecer as pessoas, incentivando seu envolvimento no planejamento e na avaliação institucionais. Um dos efeitos do empowerment é o envolvimento efetivo de todos os participantes do processo avaliativo, o que contribui para tornar a avaliação um processo mais democrático.

\section{- A avaliação precisaria desvelar critérios e indicadores a todos seus atores institucionais}

Heráclito dizia que "o que se move, conhece o que se move". (apud Abbagnano, 1998). Assim, precisamos conhecer o que está sendo avaliando para saber avaliar. Uma instituição que se conhece, detectará, com maior facilidade, seus sucessos, seus problemas, enfim, terá maior probabilidade de descobrir os meios para intervir na realidade e melhorar a qualidade de sua educação. Quando da definição de critérios, não se poderá fugir da reflexão sobre o que é qualidade, afinal ela não é um ser abstrato. Por outro lado, não pode ser medida por uma nota classificatória. Tampouco podemos restringir a concepção de qualidade às normas da qualidade total, lógica pensada pelo mundo empresarial. 
Segundo Demo (1996) toda a qualidade humana é referenciada em alguma base quantitativa, assim como toda quantidade humana contém a dimensão da qualidade.

Quando falamos de avaliação qualitativa devemos pensar não só na competência técnica dos saberes, mas da dimensão do saber-ser, ou seja, das capacidades de construir o conhecimento e nas atitudes que imprimem um comportamento ético à ação.

Para definir critérios e coletar indícios de seu alcance, temos de considerar o fato de que estamos trabalhando com situações socialmente produzidas e com seres humanos que elaboram reflexivamente suas atuações nos contextos, a partir de seus conhecimentos, sentimentos e intenções.

Para Hadji (2001), a avaliação deve ser rigorosa. Avaliar com rigor implica primeiramente definir, de modo exato, aquilo que se espera da realidade avaliada. Logo, a primeira coisa a fazer é tornar essa expectativa transparente. Em seguida, pode-se encontrar na realidade critérios e indicadores que permitam julgar se as expectativas foram satisfeitas ou não. O rigor passa por esse duplo esforço de deixar explícitas as expectativas.

$\mathrm{Na}$ avaliação de instituições educacionais, deve haver um acordo sobre os principais critérios e um mínimo de indicadores mensuráveis em relação à qualidade, sob pena de perder-se a credibilidade das ações a serem concretizadas na prática.

\section{- A avaliação deveria evitar a dicotomia entre subjetividade e objetividade, quantidade e qualidade}

Como propõe Dias Sobrinho (2002) não se pode fazer uma oposição simples entre objetividade e subjetividade ou entre processos e produtos, quantidade e qualidade, bem como entre as partes e o todo. A avaliação da educação exige que se combinem vários enfoques, metodologias, instrumentos e estratégias.

Neste momento, devemos ressaltar a necessidade de equilibrar objetividade e subjetividade. Pela objetividade, a avaliação deve zelar por instrumentos e técnicas que possam coletar informações credíveis e verificáveis. Creio que essa é uma condição que nunca deveria ser desconsiderada. O critério de objetividade é de grande importância, pois minimiza dúvidas, desconfianças. Contudo, a objetividade precisa ser acompanhada de análises de cunho mais amplo, menos ortodoxo, menos possuidor da verdade absoluta. Nesse sentido citamos Stake (apud Vianna, 2000), para quem a subjetividade precisa ser considerada. Ela pode ser 
controlada, mas não eliminada porque qualquer que seja a abordagem do avaliador, a subjetividade estará sempre presente.

É preciso pensar que nem todas as pistas são percebidas, nem todos os fatos são valorizados de modo uniforme, nem todas as interpretações são coerentes ou verdadeiras. A subjetividade é um dos fios que atravessa o tecido da investigação, o que exige nossa atenção, uma vez que trabalharemos com fragmentos, com percepções parciais num processo de permanente construção e desconstrução.

Outra dicotomia a ser evitada é a da qualidade e quantidade que são dimensões intercomplementares e não opostas. A oposição absoluta entre quantidade e qualidade constitui um falso dilema. Reforçando essa idéia, Romão (1998) cita Gramsci que diz: "Não pode existir quantidade sem qualidade e qualidade sem quantidade (economia sem cultura, atividade prática sem inteligência e vice-versa) qualquer contraposição dos dois termos é, racionalmente, um contra-senso."

Avaliar uma instituição é ir além dos números e estatísticas, é buscar compreender seus problemas e sucessos. Não se pode negar que o Brasil se encontra diante de um enorme desafio: ampliar as oportunidades de acesso à universidade, zelando pela qualidade do ensino praticado pelo sistema de educação superior. Infelizmente, como diz Panizzi (apud Leite, 2005, p.9), em alguns casos, a expansão do sistema brasileiro de educação superior associa-se à redução da qualidade do ensino.

\section{- A avaliação deveria diversificar instrumentos, técnicas e buscar respostas em diversas fontes}

Recorrendo à literatura da avaliação da aprendizagem, vemos que Condemarín e Medina (2000) dizem que a avaliação deve ser, em sua essência, plural ou multidimensional. Isso implica a necessidade de ampliar o repertório de procedimentos, técnicas e instrumentos tradicionalmente usados, para poder analisar não somente as distintas facetas desse complexo processo, mas também a diversidade de estilos cognitivos e de marcas culturais, psicológicas e afetivas dos alunos.

Creio que o mesmo princípio aplica-se a uma auto-avaliação institucional. Questionários, entrevistas, análise de documentos, discussões em grupos focais, listas de verificação, estudos de caso, observações, entre outros, deveriam servir para quantificar e descrever os resultados. A coleta multivariada de informações é fundamental para a avaliação institucional. Métodos isolados não dão conta da complexidade avaliativa. Os atores institucionais devem estar preparados para usar diferentes métodos, instrumentos e técnicas. 


\section{- A avaliação deve zelar pela análise, interpretação de dados e disseminação das informações}

A análise de dados trabalha a organização de informações e a elaboração de inferências. A interpretação atribui significado às informações organizadas e possibilita conclusões. Uma das técnicas importantes para auxiliar a análise e interpretação, descrevendo de modo mais aprofundado as informações, é a análise de conteúdo e a triangulação. Os procedimentos de análise de conteúdo possibilitam descrever, analisar e resumir tendências observadas nos documentos escritos, incluindo-se dados coletados por meio de grupos focais, entrevistas, anotações de reuniões, etc.

Para Bardin (1977), os objetivos de uma análise de conteúdo são, fundamentalmente, a ultrapassagem da incerteza, ou seja, se o que se espera ver na mensagem, segundo as questões de pesquisa, estará efetivamente contido nos resultados. $\mathrm{Na}$ análise de conteúdo, a leitura efetuada pelos avaliadores não se restringe a uma simples leitura, mas consiste na busca de um conhecimento que se encontra em um segundo plano.

A triangulação é feita pela comparação dos resultados provindos de diferentes fontes e diferentes métodos, destinados a medir um mesmo objeto. Esta técnica permite um olhar multivariado dos fenômenos avaliados.

Disseminar as informações é outro aspecto importante. A finalidade é promover uma comunicação com os vários públicos, o que exige sua cuidadosa identificação. As formas de disseminação estão diretamente relacionadas ao uso que se pretende dar à avaliação.

\section{- A dimensão mais importante da avaliação deveria ser a ética}

Todos nós sabemos da importância da ética, mas temos dificuldades em definir critérios e indicadores para verificar se ela está presente em nossas ações. No caso das instituições de ensino superior, quais seriam os critérios e indicadores de uma auto-avaliação ética?

Um dos indicadores importantes é a busca da democratização dos resultados. Os conceitos básicos de uma avaliação democrática, segundo MacDonald (apud Saul, 1988), são o sigilo, a negociação e a acessibilidade. $\mathrm{O}$ conceito fundamental que justifica a avaliação democrática é o direito à informação. Uma sociedade bem informada é condição decisiva para a melhoria da educação e condição essencial para a sua emancipação. Outro 
critério importante é a flexibilidade da avaliação, que é expressa quando ela própria se coloca em julgamento.

Stufflebeam (1971) diz que a boa avaliação requer que o próprio processo avaliativo seja avaliado, o que se denomina de metavaliação. Pela metavaliação, objetivos, metodologias, instrumentos, formas de coleta, análise e critérios de avaliação devem ser analisados de acordo com critérios pré-estabelecidos. O Joint Committee on Standard for Educational Evaluation define um conjunto de trinta diretrizes de avaliação, reunidas em quatro grandes categorias: utilidade, viabilidade, propriedade e precisão (Worthen, 2004).

A utilidade refere-se à garantia em identificar as pessoas envolvidas na avaliação, de modo a atender às suas necessidades $\mathrm{e}$ interesses; à credibilidade dos avaliadores; à seleção de informações de forma abrangente para responder a perguntas sobre o objeto avaliado; à identificação dos fundamentos para interpretar resultados; à agilidade na produção e disseminação dos resultados e à clareza das informações avaliativas.

A viabilidade indica serem necessários procedimentos práticos. Refere-se a uma avaliação planejada e realizada com previsão e antecipação das diferentes posições dos vários grupos de interesse, para que haja cooperação, e aos aspectos de boa utilização dos recursos.

A propriedade tem por objetivo assegurar uma avaliação legítima, ética, cuidadosa e que tenha respeito pelo bem-estar dos envolvidos no trabalho. Uma das diretrizes mais importantes da propriedade é o respeito à dignidade e ao valor do ser humano em suas interações com outras pessoas associadas à avaliação, de modo que os participantes não sejam ameaçados, nem prejudicados.

A precisão tem por objetivo revelar e transmitir informações tecnicamente adequadas acerca das características que determinam o valor ou mérito do objeto avaliado. Tem relação direta com uma avaliação sistemática, com decisões imediatas de reformulação dos possíveis problemas encontrados. Para garantir a precisão é necessário pensar a respeito da análise do contexto institucional em que a avaliação será feita, sobre a descrição de finalidades e nos procedimentos avaliativos, assim como na credibilidade dos instrumentos de coleta e das fontes de informação. 


\section{ALGUMAS PALAVRAS FINAIS}

Sabemos que ao longo dos anos as instituições educacionais vêm sendo solicitadas a demonstrar seus resultados à sociedade. De início, de uma forma mais velada, depois com uma certa pressão por parte dos órgãos governamentais, sobretudo com o reforço da avaliação como accountability (prestação de contas) pelos sistemas educacionais. A avaliação aparece, então, como um pré-requisito para a implementação de mecanismos de controle, de prestação de contas e de responsabilização cada vez mais sofisticados. Essa idéia surge na América do Norte e é reforçada na Inglaterra, no governo de Margareth Thatcher, trazendo as concepções do neoliberalismo. Por esse motivo, ainda verificamos uma certa polêmica com relação aos sistemas de avaliação nacional, com posições diferentes sobre esse "prestar contas".

Na visão de Vianna (2003), os altos investimentos financeiros em educação exigem, necessariamente, um projeto de avaliação que demonstre os resultados em termos de custos-benefícios, mas que não deixem de lado o componente humanista. Macpherson (1966) sugere que se interprete o termo accountability como "responsabilização". À luz dessa interpretação, a avaliação educacional deveria ser realizada considerando toda a variedade de atividades no contexto do sistema educativo, desde as atividades desenvolvidas nas salas de aula até as que se referem às políticas educacionais, o que implica responsabilidades em várias instâncias: políticas, institucionais, de gestão e pedagógicas. Nessa perspectiva, pais e demais responsáveis pelos alunos são considerados como consumidores da educação, conseqüentemente podem e devem reclamar se o produto não satisfizer às exigências de qualidade.

Willis (apud Afonso, 1999) classifica a responsabilização em diferentes dimensões. A responsabilização profissional é aquela que aponta para a formação de bons profissionais para que eles possam tomar decisões no processo ensino-aprendizagem.

Apesar das posições divergentes sobre o tema, parece não haver dúvidas sobre a importância da visibilidade social trazida pela avaliação. Em uma democracia, as informações não podem ficar centralizadas nas mãos de poucos, elas devem ser socializadas.

Com relação às instituições de ensino superior, Belloni (2000, p.38) salienta o papel de mediadora que elas deveriam ter, considerando, de um lado, os "aprendentes" e, de outro, a sociedade e o desenvolvimento científico. Mediar nesse contexto implica compromisso com a democratização do saber e das competências, com o atendimento e com a qualidade de um número maior de pessoas. A autora (op.cit) defende, 
também, a função social da avaliação institucional, considerando-a como um instrumento para o aprimoramento da gestão acadêmica e administrativa, tanto das instituições como dos sistemas educacionais, com vistas à melhoria da qualidade e de sua relevância social.

Para sintetizar as idéias aqui descritas, talvez pudéssemos destacar que:

- Cada instituição tem uma história própria, única, sendo necessário considerar o contexto em que ela está sendo avaliada.

- A participação de todos os componentes da instituição, com seus aportes, é fundamental para uma visão mais abrangente de avaliação e posterior responsabilização com as ações de melhoria.

- A diversificação de instrumentos, técnicas, momentos e opinantes visa a um olhar multivariado do fenômeno avaliativo.

- Números, medidas são parte do processo, mas não bastam. É fundamental uma análise qualitativa que permita descrever os fatos para poder melhor compreendê-los.

Agrega-se a esse rol de sugestões uma questão de natureza filosófica que proponho como premissa para as instituições de ensino superior em seu todo e para cada um de seus atores. Nesse momento, recorro a Morin (2003, p.147) que diz: "Para se reconciliar consigo, é preciso primeiro brigar consigo. É preciso distanciar-se de si mesmo para se encontrar".

\section{REFERÊNCIAS BIBLIOGRÁFICAS}

ABBAGNANO, N. Dicionário de Filosofia. Tradução Alfredo Bosi. 2. ed. São Paulo: Martins Fontes, 1998.

AFONSO, A. J. Políticas educativas e avaliação educacional. Portugal: Universidade do Minho, 1999. Instituto de Educação e Psicologia, Centro de Estudos em Educação e Psicologia.

BARDIN, L. Análise de conteúdo. Lisboa: Edições 70, 1977.

BELLONI, I. A função social da avaliação institucional. In: DIAS SOBRINHO, J.; RISTOFF, D. (orgs) Universidade descontruída. Florianópolis: Insular, 2000. 
BRASIL. Ministério da Educação e Cultura. Paiub. Brasília, 1993. Disponível em: <http://www.mec.gov.br/Sesu/paiub.shtm>

BRASIL/Decretos. Decreto-lei 10861, de 14/04/2004. Institui o Sistema Nacional de Avaliação da Educação Superior - Sinaes. Brasília: DOU, $15 / 04 / 2004$.

CONDEMARÍN, M.; MEDINA, A. Evaluación auténtica de los aprendizajes: un medio para mejorar las competencias en lenguage y comunicación. Chile: Editorial Andrés Bello, 2000.

DEMO, P. Avaliação qualitativa. São Paulo: Cortez, 1996.

DIAS SOBRINHO, J. Educação e avaliação: técnica e ética. In: SOBRINHO, J. D.; RISTOFF, D. I. (org.) Avaliação democrática: para uma universidade cidadã. Florianópolis: Insular, 2002. p.37-68.

FREIRE, P. Pedagogia do oprimido. 17. ed. Rio de Janeiro: Paz e Terra, 1987.

GOERGEN, P. Ensino superior e formação: elementos para um olhar ampliado de avaliação. In: SOBRINHO, J. D.; RISTOFF, D. (orgs) Avaliação democrática: para uma universidade cidadã. Florianópolis: Insular, 2002.

GRÉGOIRE, J. Avaliando as aprendizagens: os aportes da psicologia cognitiva. Tradução Bruno Magne. Porto Alegre: Artes Médicas, 2000.

HADJI, C. A avaliação desmistificada. Tradução de Patrícia C. Ramos. Porto Alegre: Artemed, 2001.

LEITE, Denise. Reformas universitárias: avaliação institucional participativa. Petrópolis: Vozes, 2005.

MACPHERSON, C. B. The real world of democracy. Oxford, Inglaterra: Oxford Univ. Press, 1966.

MEIRELES, C. Retrato. Disponível em: <http://www.geocities.com/ fedrasp/cecilia-meireles.html>

MORIN, E. O método 6: ética. Tradução de Juremir Machado da Silva. Porto Alegre: Sulina, 2005. 
MORIN, E. X da questão: o sujeito à flor da pele. Tradução Fátima Murad. Porto Alegre: Artmed, 2003.

ROMÃO, José Eustáquio. Avaliação Dialógica: desafios e perspectivas. São Paulo: Cortez, 1998.

RUIZ, J. Ma. Cómo hacer evaluación de centros educativos. Madrid: Narcea; S. A. de Ediciones, 1999.

SAUL, A. M. Avaliação emancipatória: desafio à teoria e à prática de avaliação e reformulação do currículo. São Paulo: Cortez; Autores Associados, 1988.

SOBRINHO, J. D.; RISTOFF, D. Avaliação democrática: para uma universidade cidadã. Florianópolis: Insular, 2002.

SOUZA, A. M. M.; DEPRESBITERIS, L.; MACHADO, O. T. M. A mediação como princípio educacional: bases teóricas das abordagens de Reuven Feuerstein. São Paulo: Editora SENAC, 2004.

STUFFLEBEAM, D. L. et al. Educational evaluation and decision making. Itaska, IL: Peacock, 1971.

VIANNA, H. M. Avaliações em debate: Saeb, Enem, Provão. Brasília: Plano Editora, 2003.

Ibrasa, 2000.

Avaliação educacional: Teoria-Planejamento-Modelos. São Paulo:

WORTHEN, B. R. et al. Avaliação de programas: concepções e práticas. Tradução Dinah de Abreu Azevedo. São Paulo: Gente, 2004.

Recebido em: maio 2005

Aprovado para publicação em: junho 2005 